\title{
Clinical Outcome of Conservative Treatment of Displaced Mandibular Fracture in Adults
}

\author{
Lipa Bodner $^{1 *}$, Sigal Amitay ${ }^{1}$, Ben Zion Joshua ${ }^{2}$ \\ ${ }^{1}$ Department of Oral and Maxillofacial Surgery, Soroka Medical Center, Faculty of Health Sciences, Ben-Gurion University \\ of the Negev, Beer-Sheva, Israel \\ ${ }^{2}$ Department of Otolaryngology Head and Neck Surgery, Soroka Medical Center, Faculty of Health Sciences, Ben-Gurion \\ University of the Negev, Beer-Sheva, Israel \\ Email: *lbodner@bgu.ac.il
}

Received September 3, 2013; revised October 1, 2013; accepted October 9, 2013

Copyright (C) 2013 Lipa Bodner et al. This is an open access article distributed under the Creative Commons Attribution License, which permits unrestricted use, distribution, and reproduction in any medium, provided the original work is properly cited.

\begin{abstract}
The article evaluates 12 cases of conservative treatment of displaced mandibular fractures in adults. Twelve cases of displaced mandibular fractures treated surgically, either by closed reduction (IMF) or open reduction internal fixation (ORIF) served as controls. Occlusion, maximal mouth opening, lateral jaw movements, neurological dysfunction (=sensory deficit), and bone remodeling were evaluated and scored in both groups, and results were compared. No significant differences were found between the two groups in all the evaluated parameters. It is concluded that in certain cases, with displacement of 2 - $4 \mathrm{~mm}$, where a surgical approach is not feasible, reasonable spontaneous reduction and bone remodeling can occur. Meticulous follow-up is mandatory.
\end{abstract}

Keywords: Mandible; Jaw Bone; Trauma; Displaced Fracture; Conservative Management

\section{Introduction}

Fractures of the mandible are generally treated by closed or open reduction [1]. The aim of the treatment is to reduce the displaced fracture and restore proper occlusion and facial contour. The closed reduction methods involve intermaxillary fixation (IMF) using splints, arch bars, or maxillomandibular fixation screws [2,3]. There are several disadvantages with IMF, including: compromised airway, poor oral hygiene, speech difficulties, impaired nutritional intake with weight loss, and disusing atrophy of the masticatory muscles. Open reduction and internal fixation (ORIF) using wires, pins, screws, or plates are among the common methods [4].

In recent years, ORIF, by allowing immediate mobilization of the mandible, has won increasing acceptance as the method for treatment of mandibular fractures [5].

Conservative management as a treatment modality is well accepted in mandibular condylar fractures [6]. Conservative treatment in cases of mandibular body fractures has been reported in children in early childhood age, [7-12] and in adults with atrophic edentulous mandible [13-15]. In some reports, closed reduction with IMF was

${ }^{*}$ Corresponding author. considered as conservative treatment [16-18].

We are unaware of reports describing conservative treatment for displaced mandibular fracture in adults.

The purpose of the present report is to follow the clinical outcome of 12 patients with displaced mandibular fracture treated conservatively in terms of restoration of mandibular function.

\section{Material and Methods}

Twenty-four cases of mandibular fracture were included in the present study. The control group $(n=12)$ was treated surgically by either closed reduction (IMF) or open reduction (ORIF).

The experimental group $(n=12)$ was also advised to undergo surgery, either closed or open reduction. However, due to personal or medical reasons, they were not operated on.

The first patient, who was the trigger for the present study, was a 34-year-old psychiatric female patient with a displaced fracture of the mandible, who "refused" to stay at the hospital for surgery. The case was evaluated by the risk management committee of the hospital, and the advice was that as the surgery she needed was not a 
life-saving procedure, it was illegal to hospitalize her against her will and/or force her toward surgery. Her parents were involved in the entire process; however, as she was an adult, they were not eligible to make a legal decision on her behalf.

For some other participants in the experimental group, there were medical contra-indications for general anesthesia due to comorbid conditions, the legal guardians were not available, or they refused general anesthesia for some personal or religious reasons.

Clinical examination of the functional state of the mandible was performed by one of the authors (LB) as part of the standardized procedure followed for all jaw trauma patients at the hospital. The examination included: occlusion, maximal mouth opening, lateral jaw movements, neurological dysfunction (=sensory deficit), and bone remodeling. Data were classified according to a numerical scale, based on the clinical dysfunction index of Helkimo [19] with modification [20]. The patients were classified as clinically symptom-free (SF), having mild symptoms (MS), or having severe symptoms (SS). The analytical description of the scale system and the indices used are presented in Table 1. Patients in both groups were followed routinely in a similar manner. The follow-up evaluation was done for an average of 12 months post-treatment. Patients in both groups were asked to self-estimate the treatment outcome, and score it as either poor, good, or excellent. A paired t-test was used to detect significant changes between the experimental and control groups.

Table 1. The index system used for evaluation of mandibular function.

\begin{tabular}{|c|c|}
\hline \multirow{3}{*}{ a) Occlusion } & Normal $=0$ \\
\hline & Mostly normal = 1 \\
\hline & Abnormal $=5$ \\
\hline \multirow{3}{*}{$\begin{array}{l}\text { b) Maximal mouth } \\
\text { opening }\end{array}$} & $>40 \mathrm{~mm}=0$ \\
\hline & $30-39 \mathrm{~mm}=1$ \\
\hline & $<30 \mathrm{~mm}=5$ \\
\hline \multirow{3}{*}{$\begin{array}{l}\text { c) Lateral jaw } \\
\text { movement }\end{array}$} & $>7 \mathrm{~mm}=0$ \\
\hline & $4-6 \mathrm{~mm}=1$ \\
\hline & $<3 \mathrm{~mm}=5$ \\
\hline \multirow{3}{*}{$\begin{array}{l}\text { d) Neurological } \\
\text { dysfunction }\end{array}$} & Normal sensation of lower lip and gum $=0$ \\
\hline & Abnormal sensation of lower lip or gum = 1 \\
\hline & Abnormal sensation of lower lip and gum $=5$ \\
\hline \multirow{3}{*}{ e) Bone regeneration } & Normal bony union $=0$ \\
\hline & Incomplete bony union = 1 \\
\hline & Non-union $=5$ \\
\hline \multirow{4}{*}{$\begin{array}{c}\text { Sum of } A+B+C \\
+D+E:\end{array}$} & Score \\
\hline & 0 = Symptom free $(\mathrm{SF})$ \\
\hline & 1 - 5 = Score 1 = Mild symptoms (MS) \\
\hline & 6 - 25 = Score 5 = Severe symptoms (SS) \\
\hline
\end{tabular}

\section{Results}

The patients' characteristics and their self-estimation of treatment outcome are presented in Tables $\mathbf{2}$ and $\mathbf{3}$ and Figures 1-4. The prevalence of mandibular function following surgical and conservative treatment is presented in Table 4. Evaluation of the function indices showed

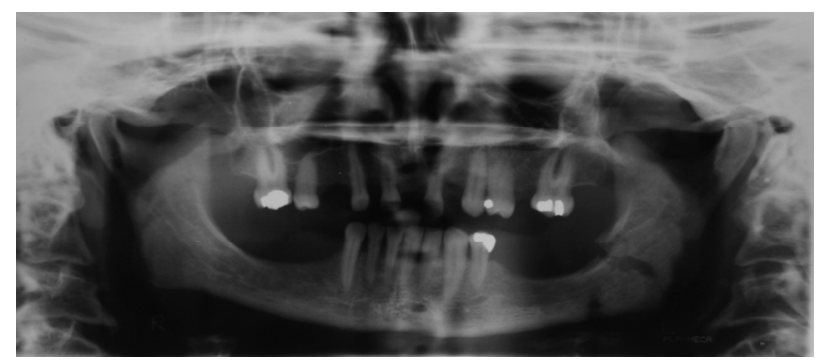

Figure 1. Fracture of Lt. angle of a dentate mandible, with 3 mm displacement, treated conservatively (Table 2 , case 1 ).

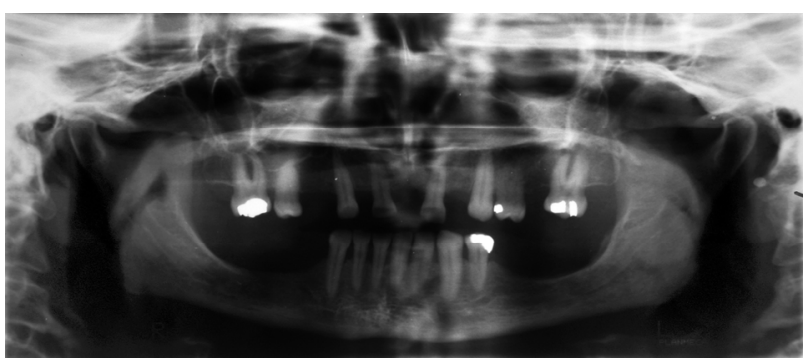

Figure 2. Outcome of the conservative treatment one year post trauma. Complete bony regeneration can be seen.

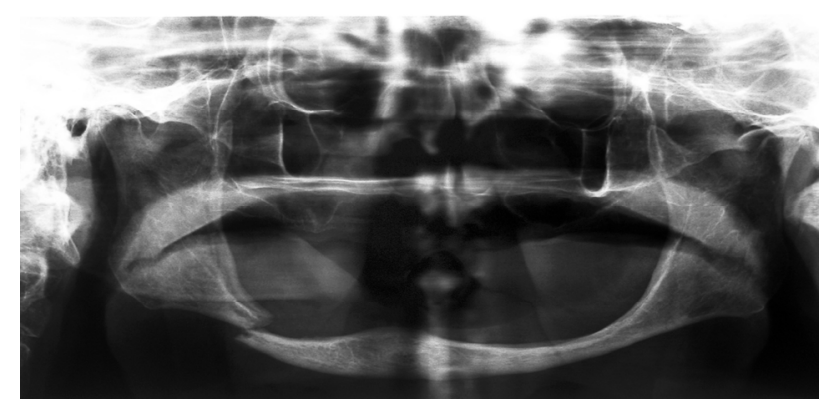

Figure 3. Fracture of the Rt. body of an edentulous mandible, with $4 \mathrm{~mm}$ displacement, conservative treatment (Table 2 , case 12).

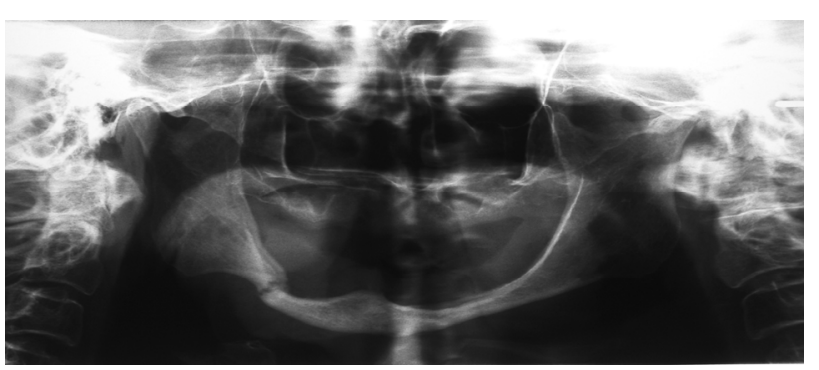

Figure 4. Outcome of the conservative treatment, one year post trauma. Good bony regeneration can be seen. 
Table 2. Characteristics of patients with displaced mandibular fracture in the experimental (conservative treatment) group.

\begin{tabular}{|c|c|c|c|c|c|c|c|}
\hline & Age & Sex & Location of fracture & $\begin{array}{c}\text { Displacement } \\
\text { Vertical/horizontal }\end{array}$ & $\begin{array}{c}\text { Dentate (D) } \\
\text { Edentulous (E) }\end{array}$ & $\begin{array}{l}\text { Reason for no } \\
\text { treatment }\end{array}$ & $\begin{array}{l}\text { Self-estimation of outcome } \\
\text { Poor/good/excellent }\end{array}$ \\
\hline 1 & 34 & $\mathrm{~F}$ & Lt. angle & 3 mm Vertical & $\mathrm{D}$ & Psychiatric & Excellent \\
\hline 2 & 43 & M & Rt. Body & 2 mm Horizontal & E & MCI & Excellent \\
\hline 3 & 71 & $\mathrm{~F}$ & Rt. Body & 3 mm Vertical & E & MCI & Good \\
\hline 4 & 62 & M & Lt. Angle & 2 mm Vertical & $\mathrm{D}$ & LSU & Excellent \\
\hline 5 & 26 & M & Rt. Angle & 2 mm Vertical & $\mathrm{D}$ & Psychiatric patient & Excellent \\
\hline 6 & 41 & M & Lt. Angle & 2 mm Vertical & $\mathrm{D}$ & LSU & Excellent \\
\hline 7 & 81 & M & Rt. Body & 4 mm Vertical & $\mathrm{E}$ & MCI & Poor-good \\
\hline 8 & 15 & M & Lt. Symphisis & 2 mm Horizontal & $\mathrm{D}$ & ALG & Excellent \\
\hline 9 & 83 & M & Lt. Parasymphisis & 2 mm Horizontal & $\mathrm{E}$ & MCI & Good \\
\hline 10 & 21 & M & Rt. Body & 2 mm Horizontal & $\mathrm{D}$ & LSU & Excellent \\
\hline 11 & 64 & M & Rt. Ramus & 2 mm Horizontal & $\mathrm{D}$ & MCI & Good \\
\hline 12 & 79 & $\mathrm{~F}$ & Rt. Body & 4 mm Vertical & $\mathrm{E}$ & MCI & Good \\
\hline
\end{tabular}

Table 3. Characteristics of patients with displaced mandibular fracture in the control (operative treatment) group (n=12).

\begin{tabular}{|c|c|c|c|c|c|c|c|}
\hline & Age & Sex & $\begin{array}{l}\text { Location of } \\
\text { fracture }\end{array}$ & $\begin{array}{c}\text { Displacement } \\
\text { Vertical/horizontal }\end{array}$ & $\begin{array}{c}\text { Dentate (D) } \\
\text { Edentulous (E) }\end{array}$ & $\begin{array}{c}\text { Type of treatment } \\
\text { IMF/ORIF }\end{array}$ & $\begin{array}{l}\text { Self-estimation of outcome } \\
\text { Poor/good/excellent }\end{array}$ \\
\hline 1 & 30 & $\mathrm{~F}$ & Lt. Angle & 3 mm Vertical & $\mathrm{D}$ & IMF & Excellent \\
\hline 2 & 43 & M & Lt. Body & 2 mm Horizontal & $\mathrm{E}$ & ORIF & Excellent \\
\hline 3 & 71 & $\mathrm{~F}$ & Rt. Body & 3 mm Vertical & $\mathrm{E}$ & ORIF & Good \\
\hline 4 & 62 & $\mathrm{~F}$ & Rt. Angle & $2 \mathrm{~mm}$ Vertical & $\mathrm{D}$ & IMF & Good-Excellent \\
\hline 5 & 26 & M & Rt. Angle & $2 \mathrm{~mm}$ Vertical & $\mathrm{D}$ & IMF & Excellent \\
\hline 6 & 41 & M & Lt. Angle & 2 mm Vertical & $\mathrm{D}$ & IMF & Excellent \\
\hline 7 & 81 & $\mathrm{M}$ & Lt. Body & 4 mm Vertical & $\mathrm{E}$ & ORIF & Good \\
\hline 8 & 15 & $\mathrm{~F}$ & Lt. Symphysis & 2 mm Horizontal & $\mathrm{D}$ & IMF & Excellent \\
\hline 9 & 83 & M & Lt. Parasymphisis & 2 mm Horizontal & $\mathrm{E}$ & ORIF & Good \\
\hline 10 & 21 & M & Lt. Body & 4 mm Horizontal & $\mathrm{D}$ & IMF & Excellent \\
\hline 11 & 64 & M & Rt. Ramus & $2 \mathrm{~mm}$ Horizontal & $\mathrm{D}$ & IMF & Good \\
\hline
\end{tabular}

Table 4. The prevalence of mandibular function following surgical and conservative treatment.

\begin{tabular}{|c|c|c|c|}
\hline & Score No. & Surgical (control) n (\%) & Conservative (experimental) n (\%) \\
\hline \multirow{3}{*}{ Occlusion } & $0=\mathrm{SF}$ & 11,92 & 10,83 \\
\hline & $1=\mathrm{MS}$ & 1,8 & 2,17 \\
\hline & $5=\mathrm{SS}$ & 0 & 0 \\
\hline & 0 & 12,100 & 12,100 \\
\hline \multirow[t]{3}{*}{ Maximal mouth opening } & 1 & 0 & 0 \\
\hline & 5 & 0 & 0 \\
\hline & 0 & 12,100 & 12,100 \\
\hline \multirow[t]{3}{*}{ Lateral jaw movement } & 1 & 0 & 0 \\
\hline & 5 & 0 & 0 \\
\hline & 0 & 10,83 & 11,92 \\
\hline \multirow[t]{3}{*}{ Neurological dysfunction } & 1 & 2,17 & 1,8 \\
\hline & 5 & 0 & 0 \\
\hline & 0 & 11,92 & 10,83 \\
\hline \multirow[t]{2}{*}{ Bone regeneration } & 1 & 1,8 & 2,17 \\
\hline & 5 & 0 & 0 \\
\hline
\end{tabular}

that generally no significant differences were found between the control and experimental groups ( $p>0.05$ ). The mean age of the patients in the control group and experimental group was 52.8 (range 18 - 83) and 51.6 (range 15 - 83), respectively. The M:F ratio was 3.0 and
2.0 in the experimental and control groups, respectively. The mean displacement was 2.50 and $2.66 \mathrm{~mm}$ in the experimental and control groups. The self-estimation of treatment outcome in the experimental group was excellent in 7 (58\%) patients, good in 4 (33.3\%) patients, and 
poor-good in 1 (8\%) patient. The self-estimation of treatment outcome in the control group was excellent in 6 (50\%) patients, good-excellent in 1 (8\%) patient, and good in 5 (42\%) patients. The differences were not significant $(\mathrm{p}>0.06)$.

The occlusion score was $92 \%$ SF and $8 \%$ MS compared to $83 \%$ SF and $17 \%$ MS in control and experimental groups, respectively. The scores for maximal mouth opening and lateral jaw movement were SF $(100 \%)$ in both groups. The neurological dysfunction score was $83 \%$ SF and $17 \%$ MS compared to $92 \%$ SF and $8 \%$ MS in control and experimental groups, respectively. Bone regeneration score was $92 \%$ SF and $8 \%$ MS compared to $83 \%$ SF and $17 \%$ MS in control and experimental groups, respectively. The differences between the control and experimental groups were not significant ( $p>0.06)$.

\section{Discussion}

The study was undertaken to determine if conservative treatment of patients with displaced mandibular fracture results in normal jaw function or with increased risk of possible dysfunction.

Reviewing the literature on complication rates of mandibular fractures revealed that it ranges from 7 to 29 per cent [21]. The complication rate has been correlated more to the severity of fracture and less to the type of treatment. No difference in complication rate was found between intermaxillary fixation and open reduction and internal fixation [22]. It was concluded that in fractures with displacement of 2 to $4 \mathrm{~mm}$, there is no difference between closed reduction and open reduction. Our interest was to look at a group of patients with displacement of 2 - $4 \mathrm{~mm}$, treated conservatively, and follow the rate of complications.

Alpert et al. [23] described four types of complications: 1) those arising in the course of proper treatment, 2) those arising due to inappropriate treatment, 3 ) those due to surgical failure, and 4) those that result from no treatment. They also gave examples for each type of complication, such as wound infection from ORIF, malocclusion from improper treatment, injury to the marginal mandibular nerve due to technical mistakes, and malocclusion from no treatment.

In the present series, 12 patients were treated conservatively. The results are more than satisfactory, as they are very similar to the results of patients treated by closed (IMF) or open reduction (ORIF). It has to be emphasized that conservative treatment does not mean "no treatment". The situation is discussed with the patient and/or with his family that under the specific circumstances, the conservative treatment is in fact the treatment of choice. The patients were routinely followed once a day, once a week, and later once a month, and the progress or no progress was evaluated per each visit. The option of changing treatment modality toward ORIF was always on the table.

Among the dentate patients, normal occlusion is the key factor that is evaluated during each follow-up visit. Also, the need to be on a liquid/soft diet is emphasized each visit. The edentulous patients were instructed not to use their dentures for several months, in order to prevent pressure-sores of the mucosa at the fracture area. Only after 12 - 16 weeks and radiographic evidence of bony union of the mandible, was the denture relined with a soft-liner and put back in place. Complete bony union and remodeling of the displaced fracture is an age-dependent process. Among the younger patients the process was faster, lasting 3 - 6 months compared to the older patients where it lasted one year or more until they were able to masticate normally with their natural teeth or dentures. Each of the patients was a unique professional challenge that was followed very carefully.

Conservative or non-surgical treatment, consisting of observation and soft diet only, has been reported as a treatment option in greenstick or non-displaced mandibular fractures with normal occlusion [24,25]. In the report by Ellis et al., [24] 687 patients, 32\% of the total sample of 2137 patients, did not undergo surgery for correction of their mandibular fracture and were observed for 4 - 6 weeks. Ghazal et al. [25] reported on 28 cases of mandibular fractures that were managed by observation and soft diet only. This conservative approach resulted in spontaneous healing of the fractures. The hypothesis is that with greenstick and non-displaced fracture, the periosteum is intact, and therefore may maintain sufficient stability for interfragmentary motion not to exceed the level tolerated by bone, thereby permitting ossification. However, in displaced fracture the periosteum is probably damaged, the gap and motion between fragments are larger, which may interfere with ossification. Therefore, the common approach is closed or open reduction.

In our series, the displacement was 2 - $4 \mathrm{~mm}$, which is considered a mild displacement. It is hypothesized that in cases with displacement larger than $4 \mathrm{~mm}$, where the risk of non-union is much greater, the conservative approach might be more risky. Similar clinical thoughts have been reported for treatment of clavicle fractures, where minimally displaced or non-displaced fractures can be treated non-surgically, whereas displaced fracture has to be treated by ORIF [26].

\section{Conclusion}

Conservative treatment of displaced fracture of the mandible carries higher risk of complications compared to IMF or ORIF. However, in certain cases, with displacement of 2 - $4 \mathrm{~mm}$, where no other treatment modality 
is feasible, it can be a treatment option with respectable results. Meticulous follow-up for these patients is mandatory.

\section{REFERENCES}

[1] H. D. Barber, S. C. Woodbury, K. E. Silverstein and R. J. Fonseca, "Mandibular Fractures," In: R. J. Fonseca and R. V. Walker, Eds., Oral and Maxillofacial Trauma, 2nd Edition, W.B. Saunders, Philadelphia, 1997, pp. 473-522.

[2] T. Imazawa, Y. Komuro, M. Inoue and A. Yanai, "Mandibular Fractures Treated with Maxillomandibular Fixation Screws (MMFS Method)," Journal of Craniofacial Surgery, Vol. 2, 2006, pp. 544-549. http://dx.doi.org/10.1097/00001665-200605000-00026

[3] D. P. Colleti, A. Salama and J. J. Caccamese Jr, “Application of Intermaxillary Fixation Screws in Maxillofacial Trauma," Journal of Oral \& Maxillofacial Surgery, Vol. 65, No. 9, 2007, pp. 1746-1750. http://dx.doi.org/10.1016/j.joms.2007.04.022

[4] T. Iizuka and C. Lindqvist, "Rigid Internal Fixation of Mandibular Fractures. An Analysis of 270 Fractures Treated Using the AO/ASIF Method," Journal of Oral \& Maxillofacial Surgery, Vol. 21, No. 2, 1992, pp. 65-69. http://dx.doi.org/10.1016/S0901-5027(05)80533-8

[5] E. Ellis $3^{\text {rd }}$, "Treatment Methods for Fractures of the Mandibular Angle," Journal of Oral \& Maxillofacial Surgery, Vol. 28, No. 4, 1999, pp. 243-252. http://dx.doi.org/10.1016/S0901-5027(99)80152-0

[6] L. A. Assael, “Open versus Closed Reduction of Adult Mandibular Condyl Fractures: An Alternative Interpretation of the Evidence," Journal of Oral \& Maxillofacial Surgery, Vol. 61, No. 11, 2003, pp. 1333-1339. http://dx.doi.org/10.1016/S0278-2391(03)00736-5

[7] C. O. Hazelrigg and J. E. Jones, "Conservative Management of a Fractured Mandible in a Ten Month Old Child," Journal of Oral Pathology \& Medicine, Vol. 40, No. 3, 1985, pp. 112-114.

[8] J. Lustmann and I. Milhem, "Mandibular Fractures in Infants: Review of the Literature and Report of Seven Cases,” Journal of Oral \& Maxillofacial Surgery, Vol. 52, No. 3, 1994, pp. 240-245. http://dx.doi.org/10.1016/0278-2391(94)90291-7

[9] S. T. Crean, V. Sivarajasingam and M. J. Fardy, "Conservative Approach in the Management of Mandibular Fractures in the Early Dentition Phase. A Case Report and Review of the Literature," International Journal of Paediatric Dentistry, Vol. 10, No. 3, 2000, pp. 229-233. http://dx.doi.org/10.1046/j.1365-263x.2000.00196.x

[10] R. Scariot, I. A. de Oliveira, L. A. Passeri, N. L. Rebellato and P. R. Muller, "Maxillofacial Injuries in a Group of Brazilian Subjects under 18 Years of Age,” Journal of Applied Oral Science, Vol. 17, No. 3, 2009, pp. 195-198. http://dx.doi.org/10.1590/S1678-77572009000300012

[11] M. Glazer, B. Z. Joshua, Y. Woldenberg and L. Bodner, "Mandibular Fracture in Children-Analysis of 61 Cases and Review of the Literature," International Journal of Pediatric Otorhinolaryngology, Vol. 75, No. 1, 2011, pp.
62-64. http://dx.doi.org/10.1016/j.ijporl.2010.10.008

[12] H. Kerem, A. Usluer and L. Yoleri, "Remodeling of a Non Treated Displaced Parasymphyeal Fracture of a Child," Journal of Craniofacial Surgery, Vol. 22, No. 4, 2011, pp. 1358-1360. http://dx.doi.org/10.1097/SCS.0b013e31821c947f

[13] M. R. Cope, "Spontaneous Fracture of an Atrophic Mandible Treated without Fixation,” British Journal of Oral Surgery, Vol. 20, No. 1, 1982, pp. 22-30. http://dx.doi.org/10.1016/0007-117X(82)90003-8

[14] K. Frame, "Conservative Management of a Patient with a Fractured Atrophic Mandible,” British Dental Journal, Vol. 162, 1987, pp. 27-28. http://dx.doi.org/10.1038/sj.bdj.4806014

[15] H. D. Barber, "Conservative Management of the Fractured Atrophic Edentulous Mandible,” Journal of Oral \& Maxillofacial Surgery, Vol. 59, No. 7, 2001, pp. 789-791. http://dx.doi.org/10.1053/joms.2001.24734

[16] V. A. Petrenko, S. V. Nudelman, E. A. Vainshtein and N. A. Golibkov, "Conservative Treatment of Mandibular Fractures,” Voenno-Meditsinky Zhurnal, Vol. 4, 1988, p. 59.

[17] E. Reinhart, J. Reuther, C. Michel, N. Kubler, H. Pistner, J. Bill and E. Kunkel, "Treatment Outcome and Complications of Surgical and Conservative Management of Mandibular Fracture," Fortschritte der Kiefer- und Gesichtschirgie, Vol. 41, 1996, pp. 64-67.

[18] M. Z. Martini, A. Takahashi, H. G. de Oliveira Neto, J. P. de Carvalho Jr, R. Curcio and E. H. Shinohara, "Epidemiology of Mandibular Fractures Treated in a Brazilian Level I Trauma Public Hospital in the City of Sao Paulo, Brazil,” Brazilian Dental Journal, Vol. 17, No. 3, 2006, pp. 243-248. http://dx.doi.org/10.1590/S0103-64402006000300013

[19] M. Helkimo, "Studies on Function and Dysfunction of the Masticatory System. II. Index for Anamnestic and Clinical Dysfunction and Occlusal State," Swedish Dental Journal, Vol. 67, No. 2, 1974, pp. 101-121.

[20] A. E. Athanasiou, B. Melsen, D. Mavreas and F. P. Kimmel, "Stomatognatic Function of Patients Who Seek Orthognatic Surgery to Correct Dentofacial Deformities," International Journal of Adult Orthodontics and Orthognathic Surgery, Vol. 4, No. 4, 1989, pp. 239-254.

[21] L. A. Passeri, E. Ellis $3^{\text {rd }}$ and D. P. Sinn, "Complication of Non Rigid Fixation of Mandibular Angle Fractures," Journal of Oral \& Maxillofacial Surgery, Vol. 51, No. 4, 1993, pp. 382-384. http://dx.doi.org/10.1016/S0278-2391(10)80350-7

[22] D. B. Lois, "Complications of Mandibular Fractures: A Comparison between Maxillomandibular versus Rigid Fixation,” Journal of Oral \& Maxillofacial Surgery, Vol. 50, Suppl. 1, 2001, p. 94.

[23] B. Alpert, M. Engelstad and G. M. Kushner, "Invited Review: Small versus Large Plate Fixation of Mandibular Fractures,” Journal of Cranio-Maxillofacial Trauma, Vol. 5, No. 3, 1999, pp. 33-39.

[24] E. Ellis $3^{\text {rd }}$, K. F. Moos and A. El-Attar, "Ten Years of Mandibular Fractures: An Analysis of 2137 Cases,” Oral 
Surgery, Oral Medicine, Oral Pathology, Vol. 59, No. 2, 1985, pp. 120-129.

http://dx.doi.org/10.1016/0030-4220(85)90002-7

[25] G. Ghazal, C. Jaquiery and B. Hammer, "Non-Surgical Treatment of Mandibular Fratures-Survey of 28 Patients," International Journal of Oral \& Maxillofacial Surgery, Vol. 33, No. 2, 2004, pp. 141-145. http://dx.doi.org/10.1054/ijom.2003.0458

[26] O. A. Van der Meijden, T. R. Gaskill and P. J. Millet, "Treatment of Clavicle Fractures: Current Concepts Review,” Journal of Shoulder and Elbow Surgery, Vol. 21, No. 3, 2012, pp. 423-442.

http://dx.doi.org/10.1016/j.jse.2011.08.053 